\title{
Designing and Building an Over Voltage Protection System for a Smart Home
}

\author{
Osama T. Rashid \\ Computer Engineering \\ Dept. \\ Iraq University College \\ Basrah, Iraq
}

\author{
Abdulmuttalib T. \\ Rashid \\ Electrical Engineering \\ Dept. \\ University of Basrah \\ Basrah, Iraq
}

\author{
Israa Sabri A. AL- \\ Forati \\ Electrical Engineering \\ Dept. \\ University of Basrah, \\ Basrah Iraq
}

\author{
Alaa I. AL-Mayoof \\ Communication \\ Engineering Dept. \\ Iraq University College \\ Basrah, Iraq
}

\begin{abstract}
The aim of this paper is to design and construct an over voltage protection system for a smart home. This system is designed to control the operation of a multi-device according to their priority and the amount of current allowed to be used for each home. The important part of the system is the main control unit, which receives the readings of the devices by using current sensors - one for each device. The algorithm used for controlling the operation of each device is implemented in software using the Visual Basic program, to show the principle of the operating system. Furthermore, the system is constructed on an Arduino microcontroller and several current sensors to measure the current drawn by each device. The same algorithm which is implemented in the software is applied to the microcontroller to save the energy drawn by the devices. The control system designed is tested in several experiments to show its performance.
\end{abstract}

\section{General Terms}

Smart home, over voltage system.

\section{Keywords}

Over voltage system, Current sensors, Arduino microcontroller.

\section{INTRODUCTION}

The consumption of electrical power is one of the main problems in smart homes. The saving and monitoring of electrical power consumption by electrical devices are the central task in designing a smart home $[1,2]$. Therefore, the efficient design of the electrical management system is the necessary requirement in a smart home. Nowadays, energy saving is crucial for every home [3-5]. Electrical power is used in our daily lives on things like lights, air conditioners, fans etc. The load control in a smart home is an important task since it protects from overloading and saves on energy consumption. The majority of this energy is spent on unnecessary usage, like cooling and heating, and this occurs because of using a poor management system.

One of the applications for energy saving in a smart home is designing a prototype dependent on using a microcontroller and several sensors to control the lights and air conditioners, as well as the fans etc. [6]. Other applications for a smart home are designed by using motion sensors with reed contacts on doors to sense the occupancy of the home, which was then used to instruct a heating system [7]. In 2013, several techniques were developed to permit energy savings [8]: (1) infrared sensors and magnetic reed switches to detect when residents are away; (2) a model with current and historic sensors is used to decide when the heating should be turned on and off; (3) a simple heuristic approach to achieve deeper setbacks when residents are away for longer periods of time. In 2011, an infrared-based WSN solution from a commercial building was used to gather real occupancy data [9]. In 2009, the researchers introduced a GPS thermostat to control the temperature, depending on the distance-to-home time of the residents, which was determined by each resident's smartphone location [10]. In 2014, another group of researchers closed that comparison gap by simulating the energy savings and comfort loss of most of the state-of-the-art approaches on a number of representative scenarios [11].

In this project, a prototype for over voltage protection and energy saving for smart homes is introduced. The prototype uses an Arduino microcontroller with various sensors such as a current sensor, as well as actuators, to control the air conditions. The principal of energy saving in this system depends on controlling the number of working devices at each moment. This process is achieved by choosing a suitable maximum load to switch the devices ON and OFF so a limited number of devices is obtained in the operation at any one time.

\section{SOFTWARE DESIGN OF THE OVER VOLTAGE PROTECTION SYSTEM}

This section described the software design of the over voltage protection system, which is based on using the Visual Basic program. Fig.1 shows the graphical user interface for the program. The designed system has ten fields for randomly choosing the current of some home devices. Some devices represent a high current load, like air conditioners, and the others by small current loads, like lights. Ten fields were also added to randomly choose the order of operation from each device. Furthermore, the form has ten fields to indicate the status of the devices (ON or OFF) after running the program. The 'combo box' is used to choose the maximum current allowed for operation. After executing the program, the actual currents used by the operating devices are shown in separate text boxes. The software used to implement this procedure is dependent on reading all of the currents drawn by the devices. The current from each device is stored in one element of a one-dimensional array. Another one-dimensional array is used to store the order of operation of each device. The maximum allowed current is selected from a combo box and stored in other variables in the program. The process of overload protection is started by sorting the array of the devices' currents in an increasable manner and, according to this new arrangement to the array, the content of the ordered array is also changed. Now the contents of the over voltage array elements are added, starting from the first element, and when the results of the addition are greater than the maximum 
allowed current, the addition process is stopped. Now all of the devices which add their current to the result must be turned on and other devices must be turned OFF.

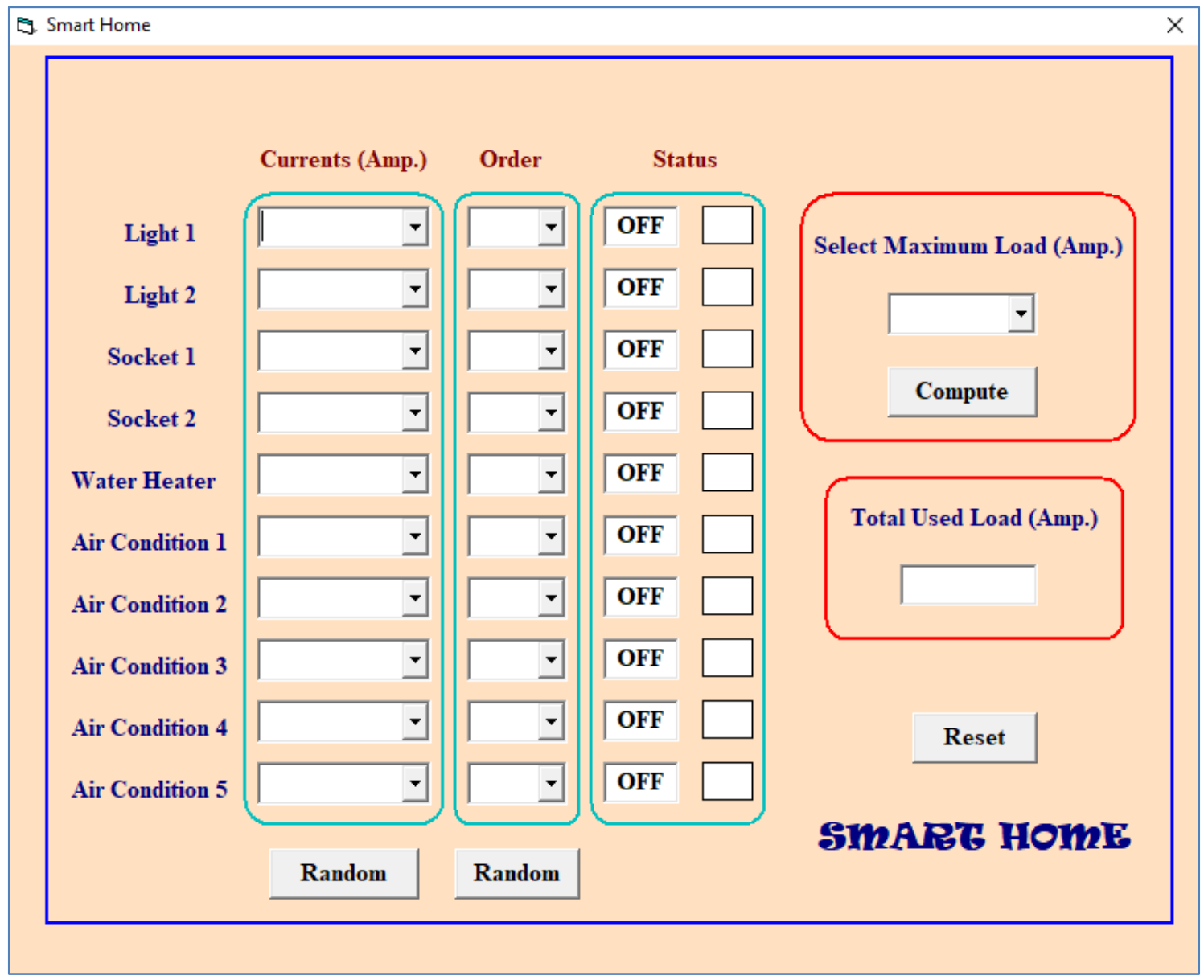

Fig. 1: Software implementation of the overload protection system.

Fig. 2 shows the flowchart for the over voltage protection program.

\section{HARDWARE DESIGN OF THE OVER VOLTAGE PROTECTION SYSTEM}

Over voltage protection and energy saving have raised a lot of interest because they provide the ability to save energy and reduce the cost to the customers. The over voltage protection system has several devices with the same structure: The main control device is represented by Arduino Mega, an ACS712 current sensor, keypad and LCD. Fig. 3 and Fig. 4 shows the prototype design and the front face of the over voltage protection system.

The Arduino Mega 2560 is a microcontroller board based on the ATmega2560. It has 54 digital input/output pins, 16 analog inputs, 4 UARTs, $16 \mathrm{MHz}$ crystal oscillators, a USB connection, a power jack, an ICSP header, and a reset button. It contains everything needed to support the microcontroller; simply connect it to a computer with a USB cable or power it with a battery to get started. The Mega is compatible with most shields designed for the Arduino.

The ACS712 is a current sensor which can detect AC or DC currents easily. The maximum values of an AC or DC which can be detected is 30A. Its operating voltage is $5 \mathrm{v}$. ACS712 is available in a small surface mount SOIC8 package. It consists of a precise linear hall circuit with a copper conduction path located near the surface of the die. When applied, a current pass through this copper conduction path generated by a magnetic field, which is sensed by a Hall integrated circuit (IC) and converted into a proportional voltage.

An LCD (Liquid Crystal Display) screen is an electronic display module. A $16 \times 2$ LCD display is a very basic module and is very commonly used in various devices and circuits. These modules are preferred over seven segments and another multi-segment LEDs. The LCDs are economical, easily programmable, have no limitations on displaying special and even custom characters, animations, and so on. A 16x2 LCD means it can display 16 characters per line and there are 2 such lines. In this LCD, each character is displayed in a $5 \times 7$ pixel matrix. This LCD has two registers, namely, 'command' and 'data'. The command register stores the command instructions given to the LCD. A command is an instruction given to an LCD to do a predefined task like initializing it, clearing its screen, setting the cursor position, controlling display etc. The data register stores the data to be displayed on the LCD. The data is the ASCII value of the character to be displayed on the LCD.

The block diagram for this device is shown in Fig. 5. This system is provided by four current sensors to measure the current drawn by four loads. Furthermore, four relays are used to switch four contactors $\mathrm{ON}$ or $\mathrm{OFF}$, which are used to control the operating of the four loads. A keypad is used to enter the initial parameters to the system, such as the maximum current allowed for operation and the order of the 
operation of each load. The result of using this system is displayed on the LCD circuit. The circuit diagram of the over voltage protection system is shown in Fig. 6 .

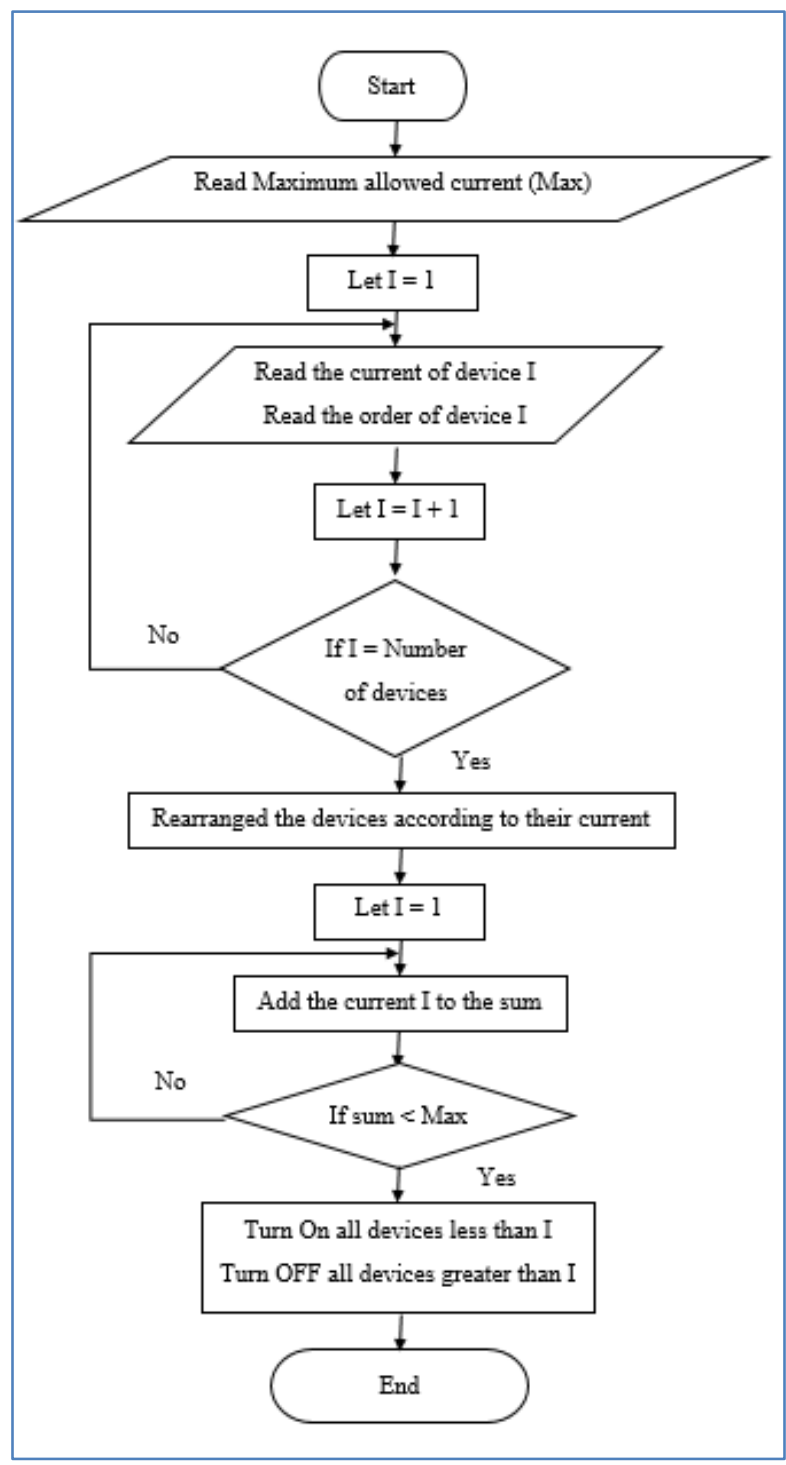

Fig. 2: Flowchart for the overload protection system.

This system operation begins by entering the initial ordering of loads and also the maximum allowed value for the current. After that, the system reads the loads current using the current sensors and rearranges this current according to the order of these loads. Subsequently, the program starts to compute the sum of the used current, starting from the first ordered load to the last one. All the devices lead to making the total drawing current below the current limit when it turned on and the other devices are turned off, as shown in the front face of the over voltage protection device (Fig. 4).

\section{EXPERIMENTAL RESULTS}

In the simulation results, the environment has ten pieces of equipment. Some of them need high currents, like air conditioners and water heaters, and others require low currents, like lights and sockets. Three cases are tested in this simulation: the first one assumes that all the devices draw small currents, as shown in Fig. 7; the second simulation assumes that all the devices draw high currents. Fig. 8 and Fig. 9 shows the case where some devices have drawn low currents and the others have drawn a high current. The percentage from the current used by devices to the maximum allowed current is compared to the three cases and shown in Fig. 10. From the comparison the maximum allowed current increases, the percentage of the used current to the maximum allowed current also increases, and the case with the small current loads produces a better percentage than the other two cases.

The experimental results are tested in the environment with one over voltage protection device which has four current sensors, four indication lamps (one for each load) and an LCD module to display the current drawn by each device.

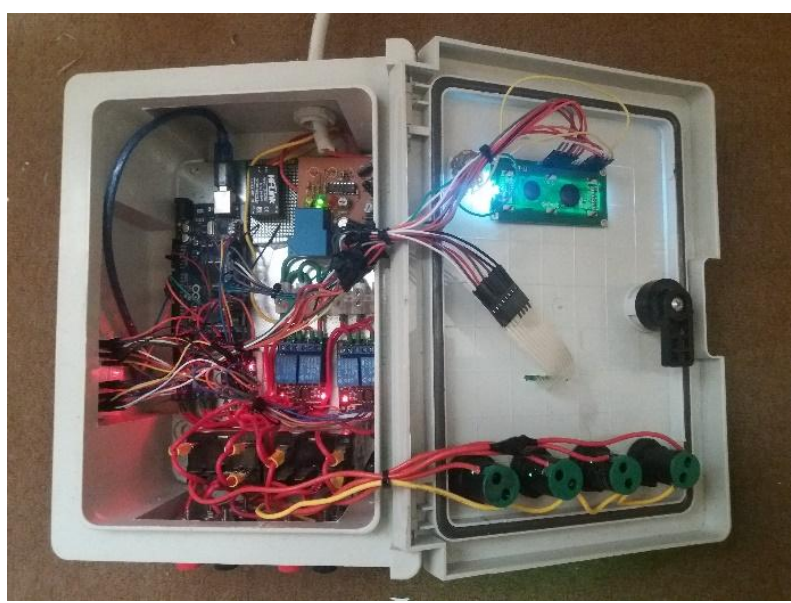

Fig. 3: Prototype design for the overload protection device.

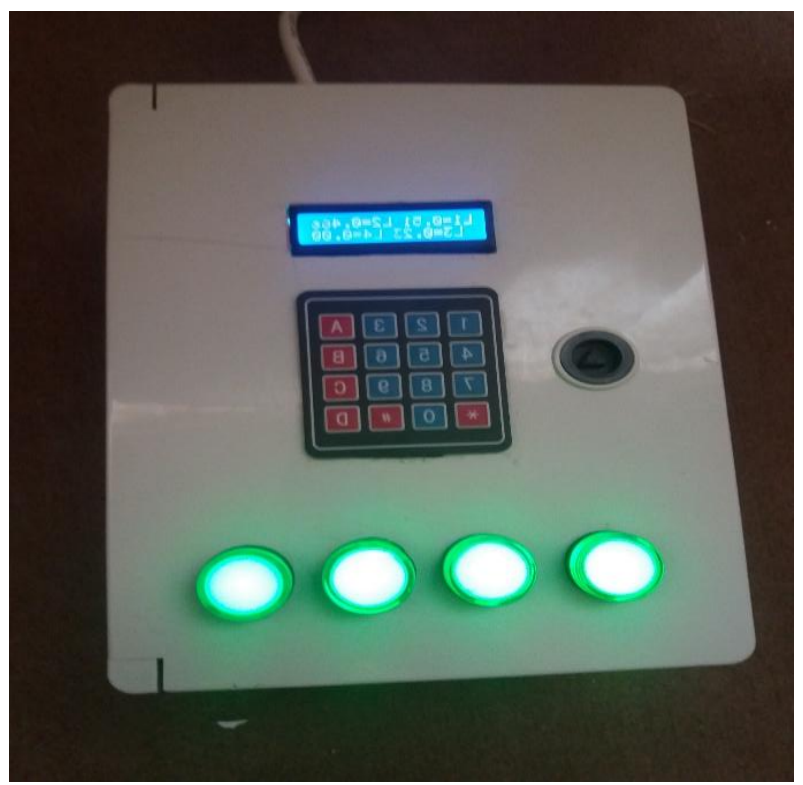

Fig. 4: Front face of the overload protection device. 


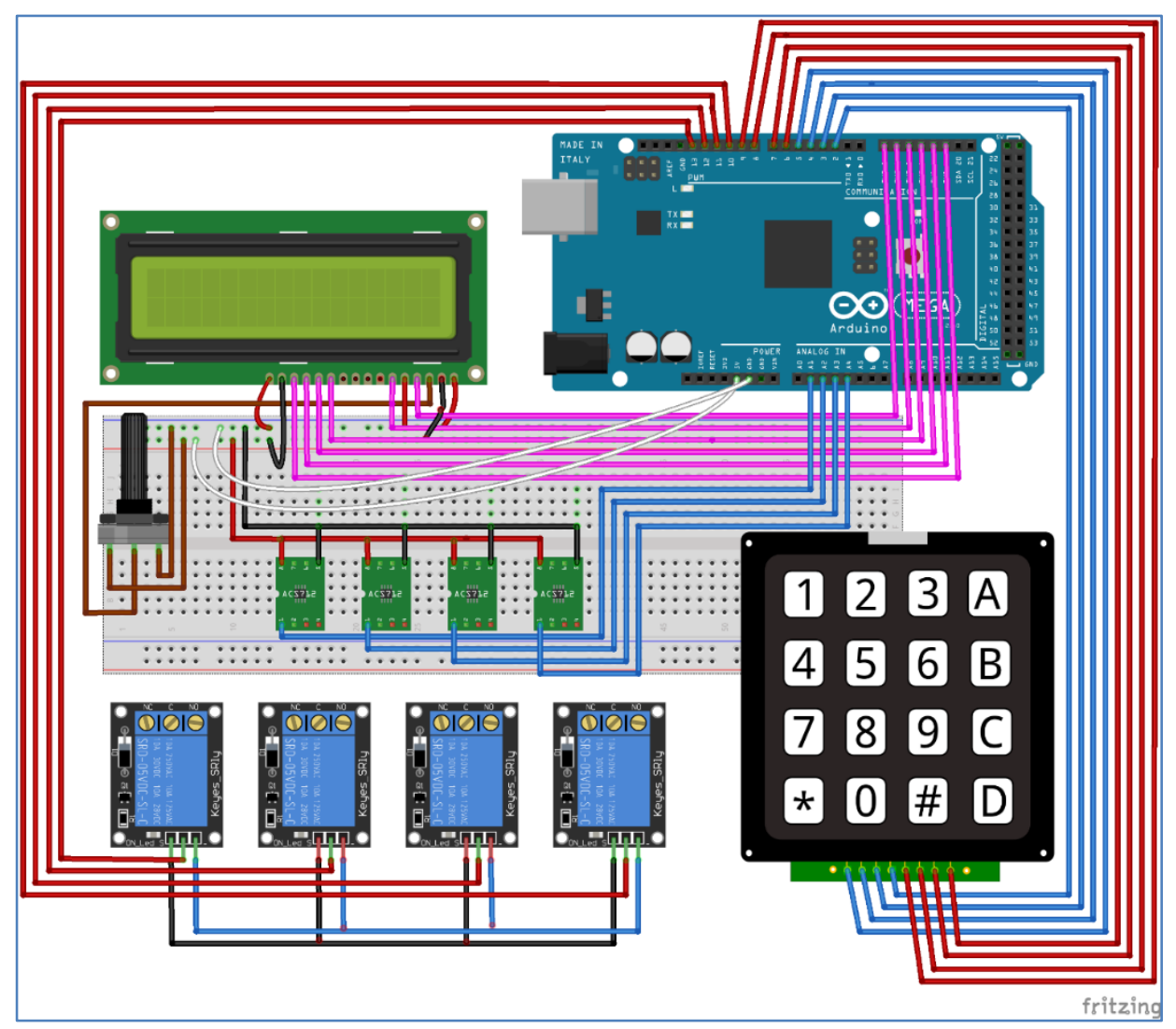

Fig. 5: Block diagram for the overload protection system.

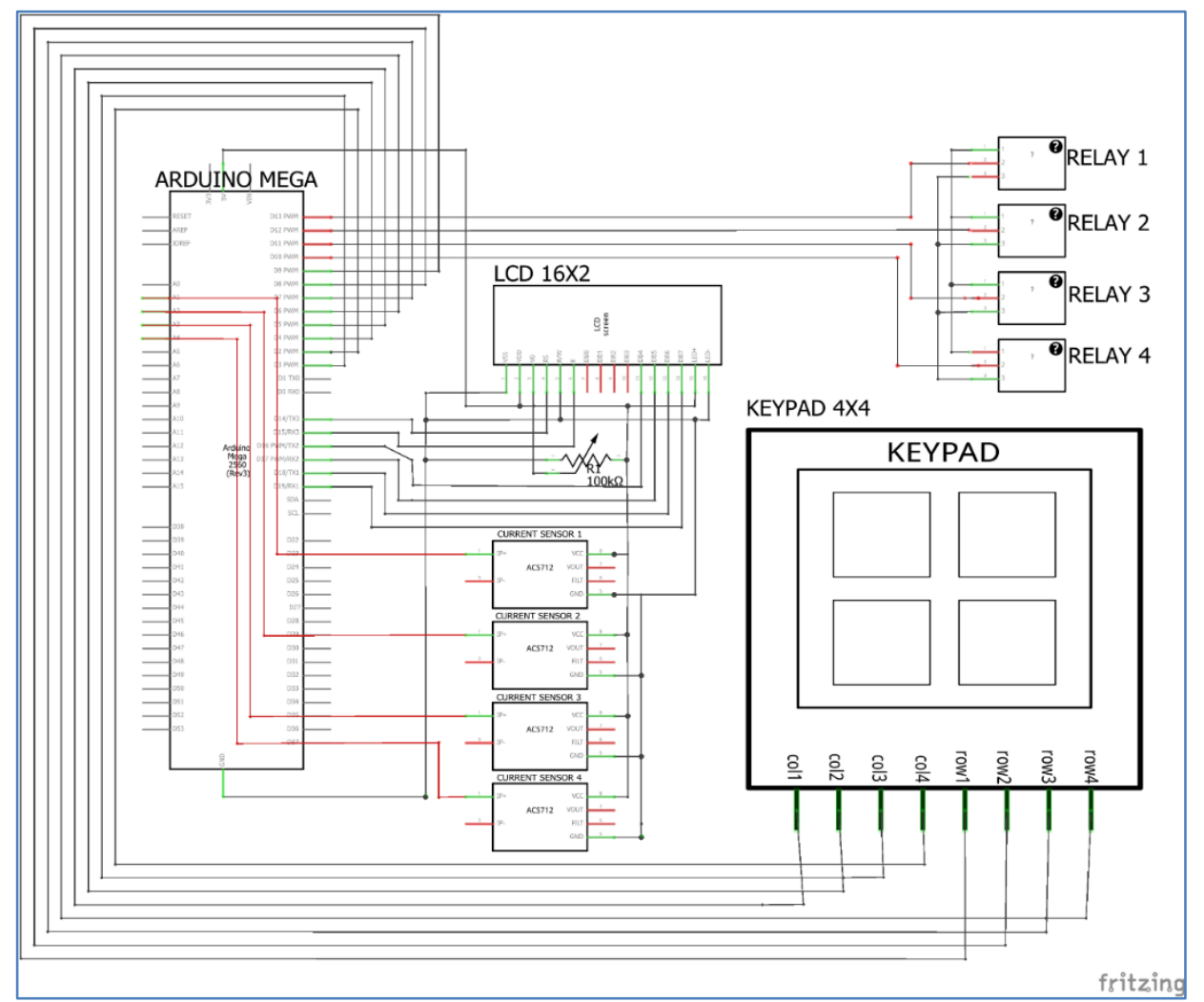

Fig. 6: Circuit diagram for the overload protection system. 


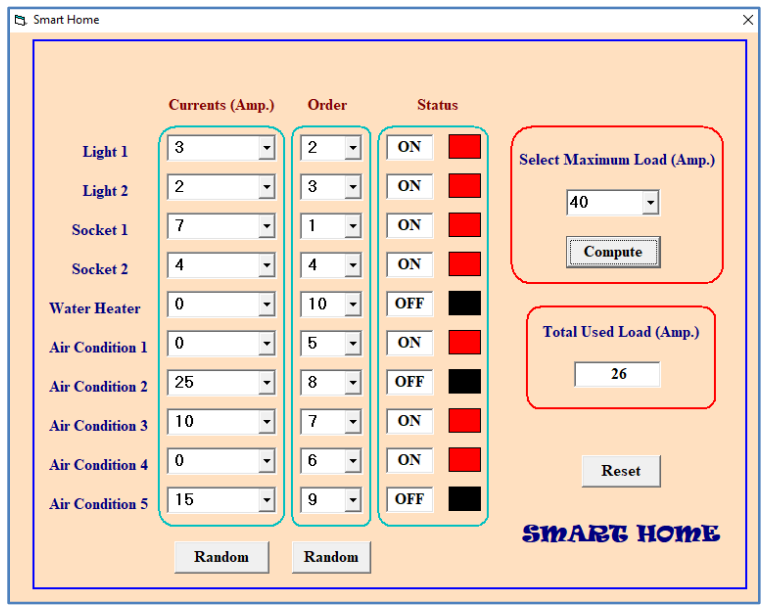

Fig. 7: The GUI with mixed current devices.

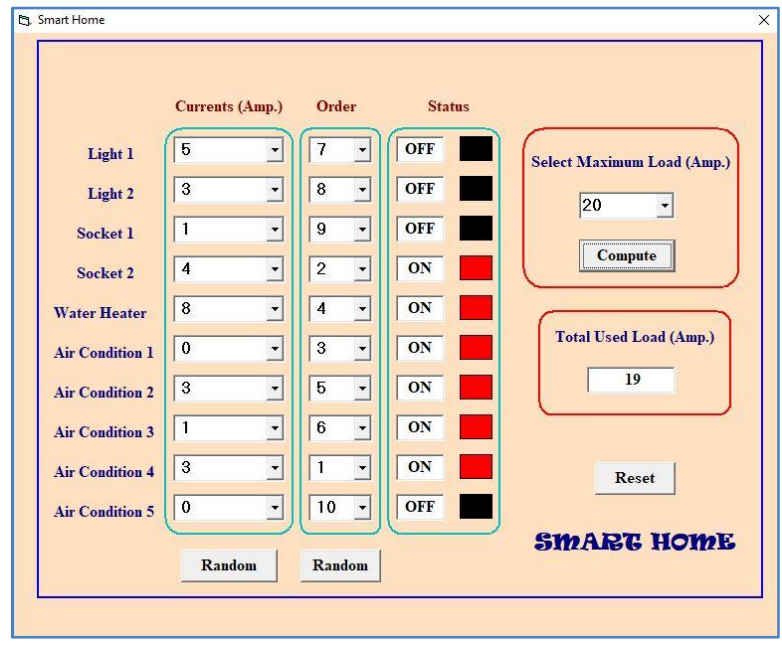

Fig. 9: The GUI with low current devices.

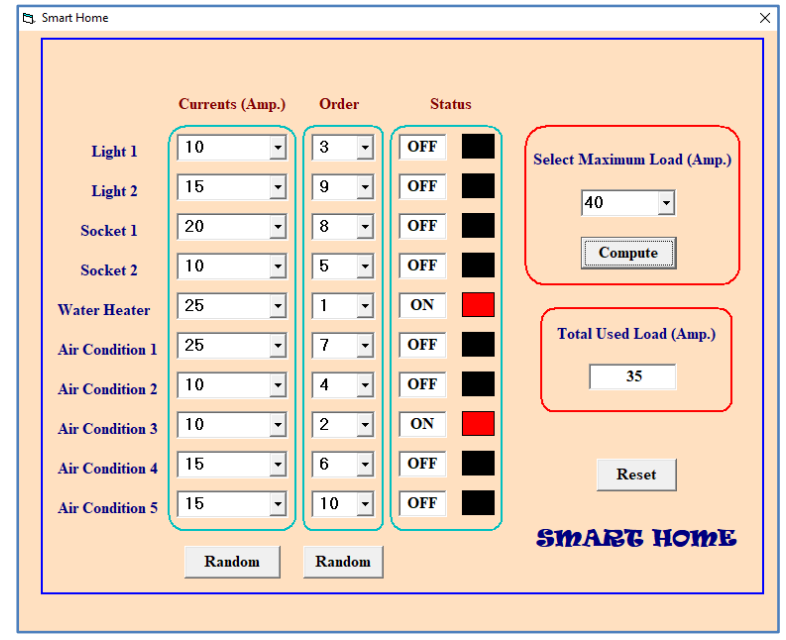

Fig. 8: The GUI with high current devices.

\section{CONCLUSIONS}

In this paper, a prototype for a over voltage protection device is designed and constructed. This system is designed on a Visual Basic program and implemented on ten loads with the control of their orders. The simulation results show that as the maximum allowed current increases, the percentage of the used current to the maximum allowed current also increases. The system with loads which have small currents produce better performances when compared with higher or mixed current cases.

The system is also built by using very cheap equipment. This system is designed to turn on devices only within the limited current and when the others are turned off. This process reduces the amount of spent energy and also reduces the cost of electricity for the users. The experiments show that the best case is obtained when the control devices have a small current.

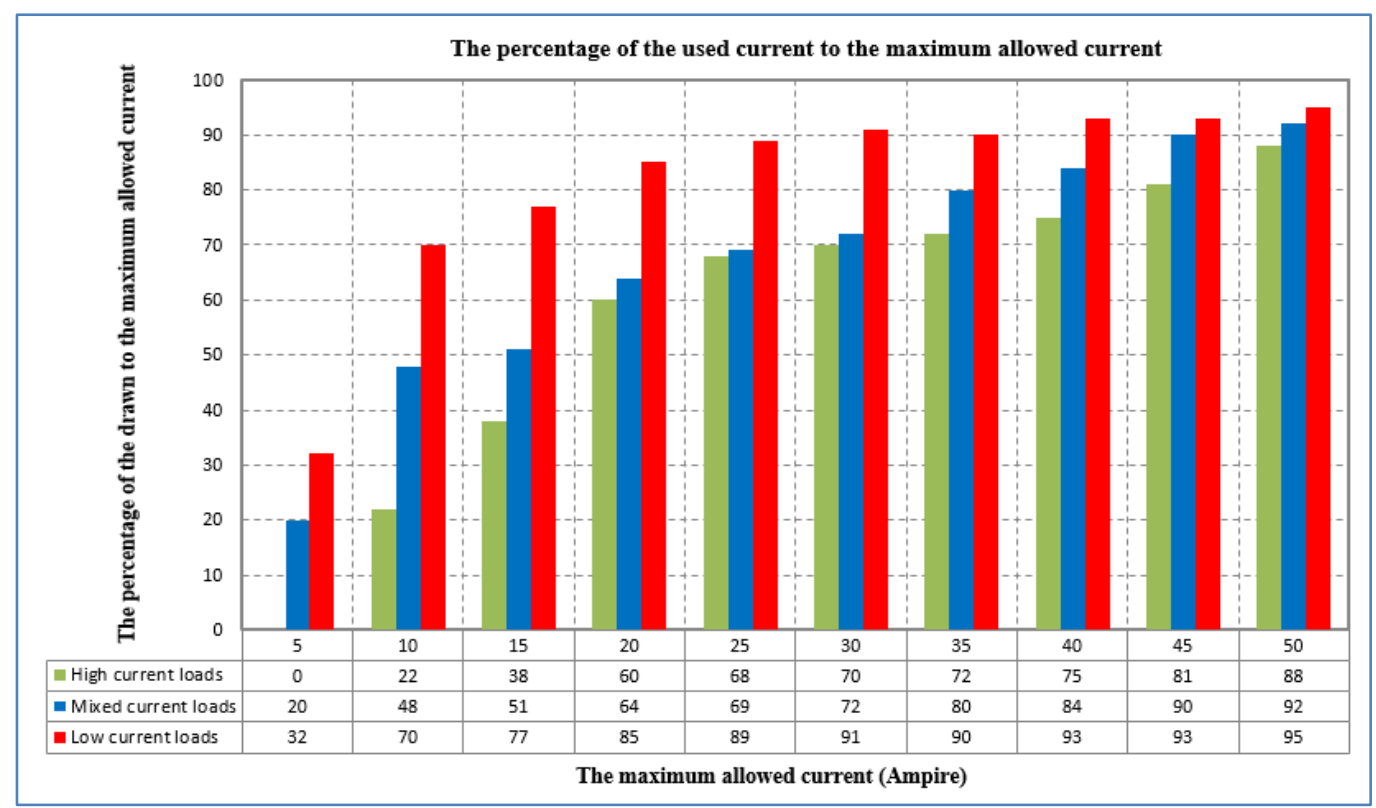

Fig. 10: Front face of the overload protection device. 


\section{REFERENCES}

[1] F. K. Handhal and A. T. Rashid, " A prototype Design for Three Phase Smart Energy Meter", Second Al-Sadiq International Conference on Multidisciplinary in IT and Communication Science and Applications, 2017.

[2] F. K. Handhal and A. T. Rashid, "Design and building a single-phase smart energy meter using Arduino and RF communication system ", Proc. of the 3rd Int. Sci. Conf., (14-15/march/2018).

[3] A. T. Rashid and M. T. Rashid," Design and Implementation of Load Balancing System for a Smart Home", Proc. of the 3rd Int. Sci. Conf., (1415/march/2018).

[4] F. K. Handhal and A. T. Rashid,, " Load Balancing in Distribution System Using Heuristic Search Algorithm “ , International Conference on Advances in Sustainable Engineering and Applications (ICASEA), Wasit University, Kut, Iraq, pp. 48-53, 2018.

[5] A. T. Rashid, F. K. Handhal and O. T. Rashid," Wireless Control system for Three Phase Loads Balancing in Distribution Networks ", International Journal of Computer Applications (0975 - 8887) Vol. 182 - No. 7, pp. 38-46, 2018.

[6] R. Panna, R. Thesrumluk and C. Chantrapornchai, “ Development of Energy Saving Smart Home Prototype
International Journal of Smart Home, Vol. 7, No. 1, pp. 47-66, 2013.

[7] [G. Gao and K. Whitehouse," The Self-Programming Thermostat: Optimizing Setback Schedules based on Home Occupancy Patterns", In Proceedings of the First ACM Workshop on Embedded Sensing Systems for Energy-Efficiency in Buildings. Berkeley, California: ACM Press, pp. 62-77, 2009.

[8] S. Lee," Occupancy prediction algorithms for thermostat control systems using mobile devices", In IEEE Transactions on Smart Grid, pp. 1332-1340, 2013.

[9] V. L. Erickson, M. A. Carreira-Perpiñán and A. E. "OBSERVE: Occupancy-Based System for Efficient Reduction of HVAC Energy. In Information Processing in Sensor Networks (IPSN), 2011 10th International Conference on. IEEE, 2011.

[10] M. Gupta, S. Intille and K. Larson, "Adding GPS-control to traditional thermostats: An exploration of potential energy savings and design challenges", In Pervasive Computing. Springer Berlin Heidelberg, pp. 95-114, 2009.

[11] W. Kleiminger, F. Mattern and S. Santini,'Predicting household occupancy for smart heating control: A comparative performance analysis of state-of-the-art approaches", Energy and Buildings, Vol. 85, pp.493505, 2014. 